\title{
First-Time Parents' Prenatal to Postpartum Changes in Health, and the Relation of Postpartum Health to Work and Partner Characteristics
}

\author{
Dwenda K. Gjerdingen, MD, and Bruce A. Center, PhD
}

Background: The purpose of this study was to evaluate prenatal to postnatal changes in first-time parents' physical and mental health, and to describe social and health predictors of parents' postpartum health.

Methods: This prospective study surveyed 261 expectant fathers and mothers during pregnancy and again at 6 months' postpartum regarding their health, partner, and work characteristics. Postpartum changes in health were evaluated by paired $t$ tests, and predictors of postpartum health were determined using multiple regression analyses.

Results: Both fathers and mothers experienced significant postpartum declines in perceived quality of life. In addition, fathers reported an increase in the number of days ill and a decrease in general health and vitality after childbirth. Mothers perceived an increase in vitality despite their diminishing sleep. Parents' postpartum health was associated with mothers' partner satisfaction, fewer illness days, and certain work characteristics, such as total work time and the balance of work between mothers and fathers.

Conclusions: Both mothers and fathers experienced declines in health that persisted at least 6 months after the birth of their first child. Notably, postpartum health was associated with partner satisfaction and work characteristics. This information might be used to develop interventions for improving parents' health during this vulnerable time. (J Am Board Fam Pract 2003;16:304-11.)

In the early postpartum period, women can experience a number of medical complications such as hemorrhage and infection. There is a growing awareness, however, that in addition to these more immediate and well-recognized conditions, new mothers may experience other postpartum health problems that persist well beyond the traditionally designated 6-week postpartum recovery period. These problems-vaginal discomfort, sexual difficulties, breast infection, fatigue, dizziness, depression, constipation, respiratory infections, and mental disorders-encompass multiple organ systems. ${ }^{1,2}$ The potential duration and breadth of postpartum disorders suggest a need for health care providers to attend to both short-term and longer term health concerns arising from reproductive and other systems. Such concerns might easily be ne-

Submitted, revised, 30 July 2002.

From the Department of Family Practice \& Community Health (DKG, BAC), University of Minnesota Medical School, Minneapolis. Address reprint requests to Dwenda K. Gjerdingen, MD, 580 Rice St., St. Paul, MN 55103.

This study was supported by the University of Minnesota Graduate School and the American Academy of Family Physicians. glected by parents and health care providers alike in light of the focus on infant care during the early months of life and a traditional lack of regular follow-up with mothers after the 6-week postpartum checkup.

A few investigators have observed that fathers, too, can experience physical and mental health disorders in the early postdelivery period. ${ }^{3-7}$ For example, a longitudinal study comparing 81 expectant and new fathers with 66 men not experiencing childbirth found that at 6 weeks after delivery, new fathers had more fatigue, irritability, headaches, difficulty concentrating, insomnia, nervousness, backache, restlessness, depression, and colds. ${ }^{3} \mathrm{Fa}-$ thers can also suffer from mental postdelivery disorders, such as depression, anxiety, and psychosis, although to a lesser degree than mothers. ${ }^{5-7} \mathrm{Al}-$ though there is some evidence that rates of more common paternal mental disorders, such as depression, increase after delivery, ${ }^{6}$ it is unclear whether these trends apply to rarer conditions, such as psychosis. In addition, there is little information about the duration of fathers' postdelivery health problems. Filling this specific knowledge gap was one goal of the present study. Using written question- 
naires, we determined for fathers and mothers how various measures of mental and physical health changed from the prenatal to the 6-month postpartum periods; we then compared these changes to look for differences by sex.

Whether the focus is on mothers or fathers, the optimization of care for new parents requires knowledge of the health and social variables that are associated with their physical and mental health during the early days of parenting. Thus, the other objective of our study was to describe predictors of parents' postpartum physical and mental health, with a specific emphasis on important social variables, such as total workload and degree of work sharing between partners. Previous work in this area has focused primarily on determining factors associated with mothers' mental health, including work-related variables, such as paid work hours and length of maternity leave; ${ }^{2,8}$ other social characteristics, including marital status, degree of marital conflict, socioeconomic status, social support, and ethnicity; $;^{2,9-11}$ and other health characteristics, such as previous mental disorders, poor general health, fatigue, sleep deprivation, thyroid disease, multiple births, and infant illnesses. ${ }^{2,10,12}$ The relatively few studies that have looked at factors related to fathers' postdelivery mental health have found that fathers' mental health is positively associated with the support they receive ${ }^{13}$ and negatively related to their partners' depressive symptoms. $^{7,14}$

The present study builds on this existing knowledge base by examining the association, for both mothers and fathers, between health (mental and physical) and previously unstudied, potentially modifiable variables, such as total workload (paid employment, plus housework and childcare) and the degree to which partners share household work. We expect that this new information will be useful to health care providers as they assist prospective parents, in particular young, dual-career families, in planning for the postdelivery period.

\section{Methods}

\section{Subjects}

Eligible for the study were English-literate men and women living together as couples (either married or unmarried) and expecting their first child. Participants were recruited from prenatal classes offered through two St. Paul HealthEast hospitals from November 1998 through August 1999. Institutional Review Boards at HealthEast and the University of Minnesota approved the study before its initiation.

\section{Procedure}

This prospective study on mothers' and fathers' postdelivery health changes was conducted as part of a randomized controlled trial that tested the benefit of a brief social support-work-planning intervention on parents' postpartum health, partner relationship, and work distribution. Because regression analyses showed no group effects on health outcomes, data from the experimental and control groups were pooled for the analyses described here.

Parents were informed about the study, gave written consent, and completed their prenatal questionnaires during the third of five prenatal class sessions. This class usually occurred during the second or third trimester of pregnancy. Parents were mailed follow-up questionnaires at 6 months postpartum.

\section{Survey Instrument}

The baseline (prenatal) and follow-up (6-month postpartum) questionnaires assessed information on physical health, mental health, partner and work measures, and demographic characteristics.

\section{Physical Health}

General Health

This 5-item scale, taken from the SF-36 Health Survey, ${ }^{15}$ elicits information about general health, health compared with that of others, and anticipated future health. Items are rated on a scale from 1 to 5 (possible range of scores: 5 to 25 , with $25=$ healthiest); the general health norm for men 18 to 34 years old is 20.6 and for women is $20.2 .{ }^{15}$ The SF-36 Health Survey is a 36-item, self-administered instrument that has been tested in numerous studies, including the Medical Outcomes Study ( $\mathrm{n}=3,445$ patients). Findings support its use across diverse populations. ${ }^{16}$

\section{Days Ill}

Participants were asked whether they had been ill during the past 4 weeks, and if so, they were asked to state the number of days that their illness had resulted in time in bed, time of reduced activity but not in bed, and time when they felt sick but con- 
tinued working as usual. These items, adapted from the National Health Interview Survey, ${ }^{17}$ were summed for total days ill.

\section{Vitality}

This scale, taken from the SF-36 Health Survey, ${ }^{15}$ consists of 4 questions that ask how often during the past 4 weeks the respondent felt full of pep, tired, worn out, or full of energy. Items are rated on a scale from 1 to 6 , with $1=$ never, $6=$ all the time (possible range of scores: 4 to 24, with 24 being most vital). The vitality norm for men 18 to 34 years old is 17 and for women is $15.8 .^{15}$

\section{Sleep}

Participants were asked how many hours of sleep they had gotten the previous night.

\section{Mental Health}

\section{Mental Health Scale}

The 5-item mental health scale is taken from the SF-36 Health Survey ${ }^{15}$ and asks how frequently, on a scale from 1 to 6 , the participant experiences various emotional states (eg, being nervous, down in the dumps, downhearted and blue, calm and peaceful, happy). The possible score range is 5 to 30 , with 30 being healthiest. The mental health norm for men 18 to 34 years old is 24.0 and for women is $23.0 .^{15}$

\section{Quality of Life}

This measure, created by Hyland and Sodergren, ${ }^{18}$ asks participants to rate their general quality of life during the previous 4 weeks on a scale of $1 \%$ to $100 \%$, with $1 \%$ being "might as well be dead," $60 \%$ "moderately good quality of life," and 100\% "nearly perfect quality of life." The average rating for a group of undergraduates was $72 \%$ and for an elderly sample $60 \% .{ }^{18}$

\section{Partner Measures}

Partner satisfaction was measured with a single item, adapted from the Kansas Marital Satisfaction Scale ${ }^{19}$ : "How satisfied are you with your relationship with your partner?" Responses are given on a scale from 1 to 7 , where 1 = extremely dissatisfied, $4=$ mixed, and $7=$ extremely satisfied.

Partner's caring was also measured with a single item, adapted from Cohen's Dimensions of Social Support Scale: ${ }^{20}$ "How often, over the past 4 weeks, did your partner make you feel he/she cared about you?" Responses are given on a scale from 1 to 7 , where $1=$ never, 7 = frequently.

\section{Work Measures}

Participants were asked to indicate the number of hours per week they spent on childcare (direct contact hours, assessed only at postpartum interval); and housework (sum of time spent on cooking, meal clean-up, house cleaning, laundry, grocery shopping, paying bills, lawn care and snow removal, and repairs). Also measured were housework sharing (single item, adapted from Bird et $\mathrm{al}^{21}$ ), the degree to which a person and a person's partner shared household responsibilities during the past month (on a scale from 1 to 7 , where 1 = partner does everything, $4=$ we share equally, and $7=\mathrm{I}$ do everything); and satisfaction with housework sharing (single item, used in previous postpartum research ${ }^{22}$, degree of satisfaction with partner's contribution to household responsibilities $(1=$ very dissatisfied, $7=$ very satisfied).

\section{Demographic Characteristics}

The prenatal questionnaire asked for participants' age, sex, education, race, and martial status. In the postpartum survey, only marital status was assessed.

\section{Analysis}

Total work hours were calculated by summing the number of hours per week spent on childcare, employment, and housework. Paired $t$ tests were used to evaluate the following:

1. Baseline (prenatal) differences between fathers and mothers (by couple) in their demographic, physical health, and mental health characteristics (listed above)

2. Significant prenatal to postnatal changes in physical and mental health

3. Father-mother differences (by couple) in prenatal to postnatal changes in physical and mental health

4. Father-mother differences (by couple) in postpartum physical and mental health

$t$ Tests and chi-square tests were used to evaluate baseline differences between the group of 261 participants who completed the study and the 39 parents who dropped out after completing the prenatal survey. For parents who completed the study, Pearson correlation coefficients were used to exam- 
ine the concordance between mothers and fathers, by couple, in prenatal and postpartum mental and physical health measures.

Internal consistency reliability for general health, vitality, and mental health were evaluated using the Cronbach coefficient $\alpha$.

Exploratory multiple regression analyses were performed for the group as a whole and for mothers and fathers separately, using postpartum general health and mental health as dependent variables. The following independent variables were used in both the general health and mental health regressions: the two partner measures (satisfaction, caring); all the work measures, plus total work hours; male-female differences in these work measures; sleep; and the demographic variables of age, education, and marital status. In addition, general health and days ill were included as independent variables in the mental health regressions, and mental health and quality of life were used as independent variables in the general health regressions. (Days ill and vitality were not included in the general health regressions, because it was thought these variables partially defined general health. Quality of life and vitality were not included in the mental health regressions for similar reasons.) For each of the regression analyses performed separately for fathers or mothers, the independent variables for both male and female participants were entered to investigate the relation of one partner's health to the health and social characteristics of the other. With the exception of age and education, independent variables were measured at the postpartum interval.

Items that were not significantly related to general health or mental health in the exploratory regression analyses conducted for men, women, or the combined group were excluded from subsequent analyses. As a result, the final regression models included the following independent variables:

1. For general health: age, education, marital status, sleep, mental health, quality of life, partner satisfaction, partner's caring, total work hours, satisfaction with housework sharing, and father-mother differences in childcare hours, housework hours, employment hours, housework sharing, and satisfaction with housework sharing
2. For mental health: age, education, marital status, general health, days ill, sleep, partner satisfaction, partner's caring, total work hours, satisfaction with housework sharing, and father-mother differences in childcare hours, housework hours, employment hours, housework sharing, and satisfaction with housework sharing

\section{Results}

A total of 722 expectant parents were informed of the study. Of these, 76 were ineligible to participate (usually because they were not living with a partner), and 346 declined to participate. Of the remaining 300 parents, 261 ( $87 \%$ of those enrolled, and $40.4 \%$ of those eligible) completed both the prenatal and postpartum questionnaires, which constituted the sample for the analyses used in this study. The sample included 129 men and 132 women, who together represented 128 complete couples. Subscale consistencies were 0.69 for general health, 0.83 for vitality, and 0.75 for mental health.

\section{Baseline Demographic and Health Characteristics}

Parents' baseline (prenatal) demographic and health characteristics, as well as significant differences by sex in these variables, are shown in Table 1. Although $95 \%$ of parents were employed at enrollment, this figure dropped to $90 \%$ at 6 months' postpartum. Ninety-two percent of parents were married, and $8 \%$ were unmarried but cohabiting (all couples were heterosexual). The $7 \%$ of participants who were not white were Asian (3\%), Latin American (2\%), African American (1\%), or of other origin. Fathers, compared with mothers, were older and more frequently employed. They also had fewer days ill and more vitality, but a lower perceived quality of life.

When baseline characteristics of parents who completed the study were compared with those who dropped out, the dropout group was found to be younger (26.3 vs 29.7 years) and less educated $(P<.001)$ and to have poorer general health and quality of life, and more days ill $(P<.05)$.

\section{Prenatal to Postpartum Changes in Health}

Several changes in health, most of which were negative, were observed for parents after the delivery of 
Table 1. Baseline (Prenatal) Demographic and Health Characteristics of Fathers, Mothers, and the Total Group, and Significant Gender Differences in these Characteristics, as Determined by Paired $t$ Tests and Chi-square Analyses $(\mathrm{n}=125-128$ Couples $)$.

\begin{tabular}{|c|c|c|c|c|}
\hline Measure & Fathers $(\mathrm{n}=129)$ & Mothers $(\mathrm{n}=132)$ & Total Group $(\mathrm{n}=261)$ & $P$ Value \\
\hline \multicolumn{5}{|l|}{ Demographic characteristics: } \\
\hline Age (mean years, SD) & $30.5(4.5)$ & $29.0(4.2)$ & $29.7(4.4)$ & .004 \\
\hline Education ( $\% \geq$ college degree) & 65.1 & 65.2 & 65.1 & 1.000 \\
\hline Married (\%) & 91.5 & 91.7 & 91.6 & 1.000 \\
\hline Employed (\%) & 98.4 & 90.9 & 94.6 & .011 \\
\hline White (\%) & 92.1 & 94.7 & 93.4 & .460 \\
\hline \multicolumn{5}{|l|}{ Physical health } \\
\hline General health* & $21.2(2.9)$ & $21.0(2.3)$ & $21.1(2.6)$ & .502 \\
\hline Days ill (d/4 wk) & $0.7(2.1)$ & $1.5(3.7)$ & $1.1(3.0)$ & .037 \\
\hline Vitality $^{\dagger}$ & $17.1(2.8)$ & $14.7(2.9)$ & $15.9(3.1)$ & .000 \\
\hline Sleep (hours last night) & $7.4(1.0)$ & $7.5(1.2)$ & $7.3(1.6)$ & .605 \\
\hline \multicolumn{5}{|l|}{ Mental health } \\
\hline Mental health scale ${ }^{\ddagger}$ & $24.6(2.6)$ & $24.4(2.4)$ & $24.5(2.5)$ & .538 \\
\hline Quality of life ${ }^{\S}$ & $82.6(11.9)$ & $86.4(8.0)$ & $84.6(10.3)$ & .001 \\
\hline
\end{tabular}

*General health: 5 items, scale $1-5$, possible score range of 5-25, with $25=$ healthiest.

${ }^{\dagger}$ Vitality: 4 items, scale $1-6$, possible score range of $4-24$, with $24=$ most vital.

${ }^{\ddagger}$ Mental health: 5 items, scale $1-6$, possible score range of 5-30, with $30=$ healthiest.

${ }^{\S}$ Quality of life: range of $1 \%-100 \%$, with $100 \%$ = best quality.

their firstborns (Table 2). Both mothers and fathers perceived significant declines in their quality of life after childbirth. In addition, fathers experienced an increase in the number of days ill and a corresponding decrease in general health and vitality. Mothers saw a reduction in their sleep hours (by 0.7 hours) and, in contrast to fathers, an increase in vitality. When fathers and mothers were compared regarding these health changes, the only measure showing a significant difference by sex in change with time was vitality, which decreased for fathers and in- creased for mothers (father-mother difference $=$ $-1.7, P=.000)$. At 6 -months' postpartum, health for fathers and mothers was similar, with only one significant difference: mothers reported having a higher quality of life than did fathers $(P=.015)$. Pearson correlation coefficients confirmed a significant, although somewhat weak, correlation between mothers and fathers in their prenatal and postpartum vitality, quality of life, and mental health, and their postpartum days ill $(r=0.2-0.4$, $P<.05)$.

Table 2. Fathers' and Mothers' Prenatal (Pre) to Postpartum (Post) Changes in Physical and Mental Health, as Determined by Paired $t$ Tests.

\begin{tabular}{|c|c|c|c|c|c|c|c|c|}
\hline \multirow[b]{2}{*}{ Measure } & \multicolumn{3}{|c|}{ Fathers $(\mathrm{n}=129)$ : means $(\mathrm{SD})$} & \multirow[b]{2}{*}{$P$ Value } & \multicolumn{3}{|c|}{ Mothers $(\mathrm{n}=132)$ : means $(\mathrm{SD})$} & \multirow[b]{2}{*}{$P$ Value } \\
\hline & Pre & Post & Post-Pre* & & Pre & Post & Post-Pre ${ }^{*}$ & \\
\hline \multicolumn{9}{|l|}{ Physical health } \\
\hline General health ${ }^{\dagger}$ & $21.2(2.9)$ & $20.7(3.0)$ & $-0.5(2.7)$ & .033 & $21.0(2.3)$ & $21.1(2.8)$ & $0.1(2.9)$ & .810 \\
\hline Days ill ${ }^{\ddagger}$ & $0.7(2.1)$ & $1.7(3.6)$ & $1.0(4.2)$ & .006 & $1.5(3.7)$ & $2.0(3.6)$ & $0.4(4.9)$ & .306 \\
\hline Vitality ${ }^{\S}$ & $17.1(2.8)$ & $16.0(3.4)$ & $-1.1(2.8)$ & .000 & $14.7(2.9)$ & $15.3(3.2)$ & $0.6(3.2)$ & .031 \\
\hline Sleep $\|^{\|}$hours last night) & $7.4(1.0)$ & $7.2(1.3)$ & $-0.2(2.3)$ & .681 & $7.6(1.2)$ & $6.9(1.2)$ & $-0.7(1.6)$ & .009 \\
\hline \multicolumn{9}{|l|}{ Mental health } \\
\hline Mental health scale II $^{\text {I }}$ & $24.6(2.6)$ & $24.2(3.2)$ & $-0.4(2.9)$ & .156 & $24.3(2.4)$ & $23.9(2.9)$ & $-0.4(2.8)$ & .101 \\
\hline Quality of life ${ }^{* *}$ & $82.7(11.9)$ & $79.3(13.1)$ & $-3.4(11.0)$ & .001 & $86.4(8.1)$ & $83.1(9.3)$ & $-3.3(9.6)$ & .000 \\
\hline
\end{tabular}

*Post-pre: postpartum score minus prenatal score.

${ }^{\dagger}$ General health: 5 items, scale $1-5$, possible score range of $5-25$, with $25=$ healthiest.

${ }^{\ddagger}$ Days ill: number of days ill during the past 4 weeks; possible range: $0-28$.

${ }^{5}$ Vitality: 4 items, scale $1-6$, possible score range of $4-24$, with $24=$ most vital.

"Due to missing data on sleep at the prenatal interval, paired $t$ tests on sleep were conducted with 39 men and 41 women. Mean postpartum sleep time, when analyzed for full sample, was 6.9 hours for both fathers and mothers.

${ }^{\mathbb{I}}$ Mental health: 5 items, scale $1-6$, possible score range of 5-30, with $30=$ healthiest.

${ }^{* *}$ Quality of life: range of $1 \%-100 \%$, with $100 \%=$ best quality. 
Table 3. Predictors of Fathers' And Mothers' General Health 6 Months after the Birth of Their First Child, as Determined by Multiple Regression Analysis.

\begin{tabular}{|c|c|c|c|c|c|c|}
\hline \multirow[b]{2}{*}{ Independent Variables } & \multicolumn{2}{|c|}{ Fathers $(\mathrm{n}=101)^{*}$} & \multicolumn{2}{|c|}{ Mothers $(\mathrm{n}=101)^{*}$} & \multicolumn{2}{|c|}{ Total Group } \\
\hline & Standardized $\beta$ & $P$ Value & Standardized $\beta$ & $P$ Value & Standardized $\beta$ & $P$ Value \\
\hline \multicolumn{7}{|l|}{ Mental health } \\
\hline Quality of life & .364 & .000 & .074 & .441 & .291 & .000 \\
\hline \multicolumn{7}{|l|}{ Work } \\
\hline $\mathrm{F}-\mathrm{M}^{\dagger}$ difference in employment hours & .252 & .006 & .108 & .332 & .150 & .027 \\
\hline Total work hours & .238 & .009 & -.069 & .497 & .061 & .372 \\
\hline $\mathrm{F}-\mathrm{M}^{\dagger}$ difference in childcare hours & .109 & .337 & -.259 & .008 & -.129 & .099 \\
\hline Demographic Education & .065 & .469 & $.254(\mathrm{~F})^{\ddagger}$ & .009 & .115 & .088 \\
\hline Adjusted $R^{2}$ & .211 & & .099 & & .089 & \\
\hline
\end{tabular}

*The number of participants included in these regression analyses is less than the total sample size, because those with incomplete data were excluded.

${ }^{\dagger} \mathrm{F}-\mathrm{M}$ refers to the father-mother difference in hours devoted to this activity.

${ }^{\ddagger} \mathrm{F}$ indicates that the standardized $\beta$ and $P$ value for this item are derived from the father's response. Otherwise, the responder identity (father or mother) is indicated by the column heading.

\section{Predictors of General Health}

Significant predictors were found for parents' general health at 6 months' postpartum (Table 3). For fathers, general health was related to quality of life $(P=.000)$, father-mother differences in paid work time $(P=.006)$, and total work time $(P=.009)$. For mothers, general health was related to motherfather differences in time devoted to childcare $(P=$ $.008)$ and to partners' education level $(P=.009)$. These factors contributed modestly to the total variance in general health scores $\left(R^{2}=0.21\right.$ and 0.10 for fathers and mothers, respectively).

\section{Predictors of Mental Health}

Parents' mental health was associated with several other health, partner, and work factors (Table 4). The most important predictor of mental health for both fathers and mothers was the mother's satisfaction with her partner $(P=.000)$. Fathers' mental health was also related to their general health $(P=$ .003 ), having smaller (vs larger) father-mother differences in paid work time $(P=.001)$, and less partner satisfaction with housework sharing $(P=$ $\left..024 ; R^{2}=0.27\right)$. For mothers, there were no additional predictors for mental health. For the group as a whole, mental health was associated with partner satisfaction $(P=.000)$, having fewer days ill $(P=.006)$, and mothers' greater contribution to childcare versus fathers $\left(P=.034, R^{2}=0.20\right)$.

\section{Discussion}

Our results show that both fathers and mothers in our sample experienced declines in physical and

Table 4. Predictors of Fathers' and Mothers' Mental Health 6 Months after the Birth of Their First Child, as Determined by Multiple Regression Analysis.

\begin{tabular}{|c|c|c|c|c|c|c|}
\hline \multirow[b]{2}{*}{ Independent Variables } & \multicolumn{2}{|c|}{ Fathers $(\mathrm{n}=100)$} & \multicolumn{2}{|c|}{ Mothers $(\mathrm{n}=100)$} & \multicolumn{2}{|c|}{ Total Group } \\
\hline & Standardized $\beta$ & $P$ Value & Standardized $\beta$ & $P$ Value & Standardized $\beta$ & $P$ Value \\
\hline \multicolumn{7}{|l|}{ Physical Health } \\
\hline General health & .277 & .003 & .135 & 133 & .116 & .077 \\
\hline Days ill & -.086 & .352 & -.087 & .338 & -.177 & .006 \\
\hline \multicolumn{7}{|l|}{ Partner } \\
\hline Partner satisfaction & $.379(\mathrm{M})^{*}$ & .000 & .461 & .000 & .398 & .000 \\
\hline \multicolumn{7}{|l|}{ Work } \\
\hline $\mathrm{F}-\mathrm{M}^{\dagger}$ difference in employment hours & -.301 & .001 & .006 & .944 & -.059 & .430 \\
\hline $\mathrm{F}-\mathrm{M}^{\dagger}$ difference in childcare hours & -.078 & .446 & -.089 & .324 & -.134 & .034 \\
\hline Satisfaction with housework sharing & $-.209(\mathrm{M})^{\dagger}$ & .024 & .005 & .961 & .120 & .062 \\
\hline Adjusted $R^{2}$ & .270 & & .204 & & .204 & \\
\hline
\end{tabular}

${ }^{*} M$ indicates that the standardized $\beta$ and $P$ value for this item are derived from the mother's response. Otherwise, the responder identity is indicated by the column heading.

${ }^{\dagger} \mathrm{F}-\mathrm{M}$ ” refers to the father-mother difference in hours devoted to this activity. 
mental well-being after giving birth to their first child. Previous postpartum studies have focused primarily on mothers' childbirth outcomes, ${ }^{1,23,34}$ but our findings indicate that fathers undergo their own postpartum experience, complete with both physical and mental symptoms that can persist for at least 6 months. In most respects, fathers' postdelivery health changes, when observed at this relatively late postpartum interval, were not significantly different from those of the mothers. The only significant difference was that fathers' vitality diminished after childbirth, while mothers' increased. This difference could be explained by mothers' low baseline vitality, likely related to their pregnant condition. By 6 months' postpartum, fathers and mothers were quite similar in their health measures, suggesting that factors other than the physical process of childbirth contributed to some of the longer range postpartum health deficits observed here, as measured by our relatively global health parameters. For example, parents' increase in illness days after childbirth (by $1.0 \mathrm{~d} / \mathrm{mo}$ for fathers and $0.4 \mathrm{~d} / \mathrm{mo}$ for mothers, $P=.006$ and .306 , respectively) might have been caused by their heightened exposures to infectious diseases, communicated by their day-care-attending infants.

Although other investigators have reported an increased prevalence of mental health disorders after delivery, ${ }^{25}$ we did not observe significant changes in Mental Health Scale scores. We may have missed such problems, however, by using a short, nondiagnostic global mental health measure and by not surveying participants in the early postpartum period, when depression is more common. ${ }^{26}$

Parents' postpartum health was related to several other health, social, and work-related factors. The strongest of these factors, mothers' partner satisfaction, was significantly related to both mothers' and fathers' mental health. This finding agrees with previous reports of relations between marital distress and many types of common and serious psychiatric disorders. ${ }^{11,27,28}$ Although our study was not designed to determine the direction of this relation, it is likely that it is bidirectional; that is, happiness and stability in a partner relationship contribute to one's general mental health, and a parent's mental well-being creates an environment in which a marriage or partner relationship can better flourish. Health professionals who assist parents during the childbearing years can help to pro- mote parents' well-being by monitoring their mental health and partner satisfaction in the months after childbirth and by providing care or referral to appropriate resources.

Parents' health was also significantly related to their work characteristics, although the nature of these relations differed between general and mental health. These contrasting relations might arise from different mechanisms. For example, fathers who work more hours than their partners at a job might be showing the healthy worker effect, whereby they work more because they are physically healthier than fathers who work less. Alternatively, when these fathers invest a great deal more time than their partners in the workforce, they might experience mental distress caused by their heavy job demands and the expectation that they are primarily responsible for the family's financial welfare. Fathers might also enjoy better mental health when they are less occupied with household chores, which is likely associated with their partners' greater dissatisfaction with housework sharing.

The study was limited by its homogenous population (mostly white, married, well-educated, employed parents), which came as a result of our selecting participants through local prenatal classes. In addition, the modest response rate makes it difficult to know whether these results can be generalized to the broader population. Given the idyllic characteristics of this sample and the finding that those parents who completed the study tended to have better health and quality of life than dropout parents, the postpartum health outcomes shown here might be overly optimistic, if anything. Although the regression analyses show important relations between parents' health and various social factors, they cannot inform us about the direction of cause and effect; confirmation of causal effects would require a more experimental approach.

These findings provide evidence of health declines among young, well-educated two-career couples-both fathers and mothers-after delivering their firstborn, with postdelivery health related to their partner satisfaction and work distribution. One can only speculate about the effects on single parents or less affluent households. Health care providers might use this information to better prepare expectant parents for the challenges of the postdelivery period and to design educational and training interventions to improve the physical and 
mental well-being of their patients during the first critical months of parenting.

The authors wish to thank Anne Marie Weber-Main, $\mathrm{PhD}$, for her editing assistance.

\section{References}

1. Gjerdingen DK, Froberg DG, Chaloner KM, McGovern PM. Changes in women's physical health during the first postpartum year. Arch Fam Med $1993 ; 2: 277-83$.

2. Gjerdingen DK, Chaloner KM. The relationship of women's postpartum mental health to employment, childbirth, and social support. J Fam Pract 1994;38: $465-72$.

3. Clinton JF. Physical and emotional responses of expectant fathers throughout pregnancy and the early postpartum period. Int J Nurs Stud 1987;24:59-68.

4. Chalmers B, Meyer D. What men say about pregnancy, birth and parenthood. J Psychosom Obstet Gynecol 1996;17:47-52.

5. Fawcett J, York R. Spouses' physical and psychological symptoms during pregnancy and the postpartum. Nurs Res 1986;35:144-8.

6. Areias ME, Kumar R, Barros H, Figueiredo E. Comparative incidence of depression in women and men, during pregnancy and after childbirth. Validation of the Edinburgh Postnatal Depression Scale in Portuguese mothers. Br J Psychiatry 1996;169:30-5.

7. Ballard C, Davies R. Postnatal depression in fathers. Int Rev Psychiatry 1996;8:65-71.

8. Hyde JS, Essex MJ, Clark R, Klein MH, Byrd JE. Parental leave: policy and research. J Soc Issues 1996;52:91-109.

9. Gazmararian JA, James SA, Lepkowski JM. Depression in black and white women. The role of marriage and socioeconomic status. Ann Epidemiol 1995;5: 455-63.

10. Albright A. Postpartum depression: an overview. J Counseling Dev 1993;71:316-20.

11. Stowe ZN, Nemeroff CB. Women at risk for postpartum-onset major depression. Am J Obstet Gynecol 1995;173:639-45.

12. Thorpe K, Golding J, MacGillivray I, Greenwood R. Comparison of prevalence of depression in mothers of twins and mothers of singletons. Br Med J 1991; 302:875-8.

13. Zelkowitz P, Milet TH. Stress and support as related to postpartum paternal mental health and perceptions of the infant. Infant Mental Health J 1997;18: 424-35.

14. Deater-Deckard K, Pickering K, Dunn JF, Golding $\mathrm{J}$. Family structure and depressive symptoms in men preceding and following the birth of a child. The
Avon Longitudinal Study of Pregnancy and Childhood Study Team. Am J Psychiatry 1998;155:81823.

15. Ware JE, Snow KK, Kosinski M, Gandek B. SF-36 Health Survey: manual and interpretation guide. Boston: The Health Institute, New England Medical Center, 1993.

16. McHorney CA, Ware JE Jr, Lu JF, Sherbourne CD. The MOS 36-item Short-Form Health Survey (SF36): III. Tests of data quality, scaling assumptions, and reliability across diverse patient groups. Med Care 1994;32:40-66.

17. Current estimates from the National Health Interview Survey. Hyattsville, Md: Department of Health and Human Services. Vital Health Stat 1985; series 10 , no. $160,1-8$.

18. Hyland ME, Sodergren SC. Development of a new type of global quality of life scale, and comparison of performance and preference for 12 global scales. Qual Life Res 1996;5:469-80.

19. Schumm WR, Paff-Bergen LA, Hatch RC, et al. Concurrent and discriminant validity of the Kansas Marital Satisfaction Scale. J Marr Fam 1986;48: 361-87.

20. Schaefer C, Coyne J, Lazarus RS. The health-related functions of social support. J Behav Med 1981;4: 381-406.

21. Bird GW, Bird GA, Scruggs M. Determinants of family task sharing: a study of husbands and wives. J Marr Fam 1984;May:345-55.

22. Gjerdingen DK, Chaloner K. Mothers' experience with household roles and social support during the first postpartum year. Women Health 1994;21: 57-74.

23. Gruis M. Beyond maternity: postpartum concerns of mothers. MCN Am J Matern Child Nurs 1977;2: 182-8.

24. Harrison MJ, Hicks SA. Postpartum concerns of mothers and their sources of help. Can J Public Health $1983 ; 74: 325-8$.

25. Kendell RE, Rennie D, Clarke JA, Dean C. The social and obstetric correlates of psychiatric admission in the puerperium. Psychol Med 1981;11: $341-50$.

26. Stuart S, Couser G, Schilder K, O'Hara MW, Gorman L. Postpartum anxiety and depression: onset and comorbidity in a community sample. J Nerv Ment Dis 1998;186:420-4.

27. Fraenkel P, Markman H, Stanley S. The prevention approach to relationship problems. Sex Marital Ther 1997;12:249-58.

28. Zelkowitz P, Milet TH. Postpartum psychiatric disorders: their relationship to psychological adjustment and marital satisfaction in the spouses. $\mathrm{J} \mathrm{Ab-}$ norm Psychol 1996;105:281-5. 